\title{
Internationally Cross-Listed Stock Prices During Overlapping Trading Hours: Price Discovery and Exchange Rate Effects
}

\author{
Joachim Grammig $^{\mathrm{a}}$, Michael Melvin ${ }^{\mathbf{b}^{*}}$, and Christian Schlag
}

\begin{abstract}
We analyze exchange rates along with equity quotes for 3 German firms from New York (NYSE) and Frankfurt (XETRA) during overlapping trading hours to see where price discovery occurs and how stock prices adjust to an exchange rate shock. Findings include a) the exchange rate is exogenous with respect to the stock prices; b) exchange rate innovations are more important in understanding the evolution of NYSE prices than XETRA prices; and c) most (but not all) of the fundamental or random walk component of firm value is determined in Frankfurt
\end{abstract}

JEL classification: F3; G15

Keywords: international stock markets; cross-listing; price discovery

\footnotetext{
${ }^{a}$ Department of Economics, University of Tübingen, Tübingen, Germany

b* Corresponding author, Department of Economics, Arizona State University, Tempe, AZ, USA, , Tel.:

+1-480-965-6860; fax: +1-480-965-0748. Email address: mmelvin@asu.edu.

${ }^{\mathrm{c}}$ Faculty of Economics and Business Administration, Goethe-University, Frankfurt am Main, Germany
}

\section{Acknowledgements}

For comments on an earlier draft, thanks are due to the editor, Franz Palm, an associate editor, three anonymous referees, Marcelo Fernandes, Andrew Karolyi, Pierre Giot, Paolo Paruolo, participants at the American Finance Association, European meeting of the Econometric Society, European Economic Association, European Financial Management Association, Sonderborg Conference on Microstructure and High Frequency Data, the Georgia Tech International Finance Conference, and seminars at the City University of Hong Kong, Hong Kong Polytechnic University, Nanyang Technological University and the Universities of Arizona, Frankfurt, Goettingen, and St. Gallen. We retain responsibility for any remaining errors. 


\section{INTRODUCTION}

Stocks of many non-U.S. firms are traded in the United States. The issue of where price discovery occurs for such firms is surprisingly understudied. For instance, we lack evidence that yields a firm answer to the question of whether U.S. trading follows the home market or the home market follows the U.S. Furthermore, how do the prices in both markets adjust to an exchange rate shock? Does arbitrage avoidance require both markets to simultaneously adjust to a new exchange rate or does the adjustment tend to occur all in one market?

While there is no paper that attempts to address both of these issues as will be done here, there is a literature that addresses the relationship between prices of foreign equities and their U.S. listings. This literature is overwhelmingly focused on lowfrequency daily returns so that issues of non-synchronous prices are potentially important. Exceptions include Ding, Harris, Lau, and McInish (1999), who examine the links between Singapore and Malaysia trading for one Malaysian firm and Eun and Sabherwal (2003) who examine the links between U.S. and Canadian trading for a sample of Canadian firms. These studies show significant price discovery in both the home and foreign market. While these papers are innovative and instructive, they differ from the analysis developed below in that they do not model the exchange rate process, but use exchange rates to convert equity prices into common units across countries. In addition, their samples have more time-aggregation between observations than the sample employed below. Harris, McInish, and Wood (2001) examine high-frequency spread and transaction price dynamics for Daimler-Chrysler after the creation of the global ordinary DCX shares and show how U.S. interest in DCX trading decreased in the first six months following the merger of Daimler-Benz and Chrysler. 
While analysis in an intra-day setting is required to provide hard evidence, lowerfrequency studies have found an independent effect of the U.S. market. For instance, Kim, Szakmary, and Mathur (2000) use daily data on 21 Japanese, 21 British, 5 Dutch, 5 Swedish, and 4 Australian firms to estimate VAR models of the impact of the underlying shares, the New York afternoon exchange rate, and the U.S. market index on ADR prices. They find that the underlying shares appear to be most important, but there is a significant independent role for the exchange rate and the U.S. market index in pricing ADRs. While their paper does not specifically address the issue of price discovery, their findings of a role for the U.S. factor suggest that the issue of price discovery requires a more detailed analysis. Other studies using daily data on individual stocks have focused on other markets. Kato, Linn, and Schallheim (1990) examine 7 U.K., 8 Japanese, and 8 Australian stocks also traded in New York and find evidence that the price in the home country leads the price in New York. They convert home country prices into dollars using a daily exchange rate taken from the Wall Street Journal. Lau and Diltz (1994) study 7 Japanese stocks also traded in New York and find bi-directional causality but a stronger impact of NYSE returns on Tokyo returns than the reverse. They convert the Tokyo prices into dollars using daily exchange rates from the Chicago Mercantile Exchange. Lieberman, Ben-Zion, and Hauser (1999) examine 6 Israeli stocks that are listed in New York and find that price discovery appears to occur in Israel for five of the firms with Teva having a dominant role for the U.S. They suggest that the result for Teva is due to Teva being a multinational firm. Their study converts the Israeli prices into dollars using a daily exchange rate from the Bank of Israel. Wang, Rui, and Firth (2002) examine a group of Hong Kong stocks that are also traded in London and find bidirectional causality for local market returns between the two markets but with Hong Kong being the dominant market. The exchange rate is not incorporated into their analysis. 
The evidence from low-frequency daily data indicates that the issue of price discovery for cross-listed shares is rather unsettled. Generally, the papers are not actually conducting tests for price discovery in the recent sense of the word but are examining pricing links across markets. One may draw inference, however, that while the majority of low-frequency evidence points toward the home market as being the dominant source of pricing, results are mixed and some studies find the U.S. prices to be dominant. Aside from Kim, Szakmary, and Mathur, the low-frequency studies do not allow for an independent role of the exchange rate but, instead, translate home market prices into dollars.

One goal of this paper is to provide evidence on the information shares of U.S. and home market trading using contemporaneously sampled, high-frequency data. A second goal is to provide evidence on the equity price response at home and in the U.S. to an exchange rate shock. There is a large literature on the effect of exchange rate changes on equity prices, but this literature has focused on the foreign exchange exposure effect of exchange rate changes for a single firm in its home country. Such studies have (quite properly) conducted analyses at a low time series frequency as they were concerned with issues related to the management of foreign exchange risk exposure. There is a limited literature that examines higher-frequency evidence of exchange rate changes and stock prices. Karolyi and Stulz (1996) examined the determinants of correlations between open to close daily returns on 8 Japanese stocks traded in the United States with a matched sample of U.S. stocks. Their data included daily returns on yen/dollar futures contracts. They found that shocks to the currency futures returns had no measurable influence on the Japanese and U.S. stock price correlations. Bailey, Chan, and Chung (2000) studied the impact of the Mexican peso/U.S. dollar exchange rate on prices of Mexican firms traded on the NYSE. They sampled stock prices and exchange rates at 30-minute intervals and found that peso depreciation was associated with decreases in the stock 
prices. Ours is the first study to examine the high-frequency response of pairs of internationally cross-listed equity prices to exchange rates at the time resolution relevant for arbitrageurs.

One might think of price discovery for a U.S.-listed European stock, e.g. the German Deutsche Telekom to be determined in the following way. News in Germany is most important for this stock, so during home market business hours, the price fluctuates with public and private information revelation. Once U.S. trading begins in the ADR, ${ }^{1}$ the price of the stock may include relevant information coming from the North American market as inventory and information-based trading occurs during the overlap between European and American trading hours. In addition, dollar/euro exchange rate fluctuations will have implications for the stock prices in both Europe and America. After an exchange rate shock, arbitrage will restrict the ADR price so that it does not deviate too far from the home market price when both are measured in a common currency. For instance, dollar depreciation would tend to increase the dollar price of the ADR and/or lower the euro price of the underlying home-market shares. Since there has been no intra-daily analysis of how international stock prices adjust to exchange rate shocks, we do not know if adjustment is symmetric in both the home country and the U.S. markets or if most or all of the adjustment to an exchange rate shock occurs in one market location. Our analysis will provide a first look at this issue.

The use of high-frequency, intra-day data allows a view of the market dynamics that cannot be achieved in daily data or lower-frequency intra-day data. Besides the issue of non-synchronous quotes that arises in using closing prices from different international markets, one cannot make meaningful inferences regarding price discovery except at the high-frequency relevant for actual trading. Furthermore, the pattern of adjustment of stock prices to exchange rate shocks would be lost due to time aggregation. Traders

\footnotetext{
${ }^{1}$ Foreign firms typically list in the United States in the form of American Depositary Receipts (ADRs).
} 
respond quickly to new information, so to infer the stock price response to an exchange rate shock one must examine the data immediately after the change in the exchange rate. At a low frequency, there will be many reasons why stock prices change so that one cannot clearly identify the link between a change in the exchange rate and a subsequent change in the price of a stock. The gain from using high-frequency data is essentially that there may be one-way causality existing among variables at a high sampling frequency that dissolves into contemporaneous correlation at a lower sampling frequency.

We investigate the issue of price discovery for three large German blue-chip firms that are traded on the XETRA system in Germany and the New York Stock Exchange (NYSE) in the United States: Daimler-Chrysler, Deutsche Telekom, and SAP. The paper is organized as follows: Section 2I presents a brief overview of relevant institutional detail regarding the trading venues, trading mechanisms, and firms studied. Section 3 introduces the basic equilibrium relationships in the context of a simple microstructure model of the market. Section 4 provides the framework for analysis and discusses issues of methodology. Section 5 presents and discusses the data and estimation results. Finally, a summary and conclusion is provided in Section 6.

\section{INSTITUTIONAL DETAILS}

Many European stocks (like in our sample Deutsche Telekom (DT) and SAP) are traded in the United States in the form of ADRs listed on the NYSE. This dollardenominated U.S. trading is not an exchange of actual shares of the firms, but rather trade in negotiable instruments issued by a depositary bank that represent ownership of the underlying shares as issued in the home market. For example, DT ADRs trade one-forone and SAP ADRs at a 12 to 1 ratio against the underlying shares. This means that 12 
SAP ADRs are issued for each share of the underlying stock held by the depositary. ${ }^{2}$

DaimlerChrysler (DCX) is traded in the United States as a global registered share (GRS), sometimes called a "global ordinary." This is a single security that is traded globally although it is quoted and settled in U.S. dollars in New York and euros in Frankfurt. ${ }^{3}$ DCX is traded on the NYSE in the United States. German trading in these firms occurs via the electronic trading network known as XETRA.

XETRA is the electronic trading system of the Deutsche Börse, the Frankfurt Stock Exchange (FSE). Trading on the FSE occurs on the floor of the exchange as well as on XETRA. The FSE floor operates in a similar manner to the NYSE floor. The equivalent of the NYSE specialist is the amtlicher Kursmakler. The makler quotes bid and ask prices and conducts daily call auctions at the Frankfurt opening (9:00), noon, and at the close of floor trading at 13:30. Since FSE floor trading ends before the NYSE opens, our data will come from the XETRA system, which overlaps with the NYSE morning. XETRA is an order-driven system with no designated market makers. It is an anonymous, open limit order book. XETRA has no designated market makers, but the FSE maklers are allowed to participate on XETRA and there is much voluntary market making. ${ }^{4}$ Banks and institutional investors are main providers of liquidity through the limit orders they submit to the market.

ADRs are issued by a depositary bank accumulating shares of the underlying foreign stock. Since ADRs are issued at a fixed multiple relative to the underlying shares, they tend to trade in a very limited range around the price of the underlying share, exchange-rate adjusted. However, ADRs and underlying shares are close, but not perfect,

\footnotetext{
${ }^{2}$ Following a 3 to 1 stock split on 1 May, 2000, SAP ADRs now trade at a 4 to 1 ratio against the German shares.

${ }^{3}$ See Karolyi (2003) and Harris, McInish, and Wood (2001) for a detailed analysis and discussion of the DaimlerChrysler global ordinary stock.

${ }^{4}$ Theissen (2002) provides a discussion of the FSE and XETRA. For small cap stocks traded on XETRA, there exist "designated sponsors" who act as market makers by submitting limit buy and sell orders simultaneously.
} 
substitutes. First, they are priced in U.S. dollars and trade and settle just as any other stock in the United States. The dollar price of the ADR will differ from the home market price by a factor incorporating the exchange rate. In addition, foreign exchange risk might influence the differential between the ADR and home market share prices. One can, in principle, arbitrage the price difference between the ADR and underlying shares by new ADR issues or cancellations. This is not a riskless arbitrage due to the time required to convert underlying shares into ADRs or cancel ADRs and convert into underlying shares. In addition, there are conversion fees, the presence of the intermediary depositary bank, and possible voting and other corporate control rights that may differ between holders of the underlying shares and holders of the ADRs. For these reasons, ADRs are not perfect substitutes for the underlying shares. Still, we expect the prices of the two assets to move closely together over time.

GRSs differ from ADRs in that they do not involve a depositary intermediary and have no issues of conversion between different forms since the same security is traded internationally. Since the GRS is quoted in local currency in each market location, prices will differ across markets by an exchange rate factor. In general, global ordinary shares should be very close substitutes across international markets as they allow all stockholders to participate in corporate matters (dividends, distributions, and control issues) regardless of their location. They may not be perfect substitutes since there is local settlement and there may be less than perfect coordination across the multinational settlement institutions involving transfer and clearance issues. ${ }^{5}$

Beyond the issue of perfect substitutability, there may also exist "limits of arbitrage" in the sense of Shleifer and Vishny (1997). In this setting noise traders generate deviations of prices from fundamental values that may persist for some time. Such deviations are not easily exploited by arbitragers risking other peoples' capital and

\footnotetext{
${ }^{5}$ Karolyi (2003) provides a good review of the differences between ADRs, GRSs, and home market shares.
} 
subject to short-term performance constraints. However, in our setting of two stocks traded simultaneously for the same firm, an arbitrage strategy is straightforward and relatively easy to implement. Therefore, in normal times we expect (and observe) the law of one price holding for ADRs and home-market stocks. Only in extreme circumstances, such as during a financial crisis as discussed in Melvin (forthcoming), do we ever see persistent deviations from the law of one price for ADRs and home-market shares. In such cases, arbitrage is ineffective in the manner discussed by Shleifer and Vishny. 


\section{INTERNATIONAL EQUITY TRADING AND EQUILIBRIUM RELATIONSHIPS}

Equilibrium in the market for U.S.-traded shares and the underlying home-market shares involves the dollar price of the ADR or GRS, the home-market price of the underlying shares, and the exchange rate. We motivate the empirical analysis by first presenting a simple microstructure model where price discovery is assumed to occur in the home market. We assume that the log of the exchange rate at time $t, E_{t}$, is exogenous with respect to U.S. and home-market shares and evolves as a random walk with innovation $u_{t}$ :

$E_{t}=E_{t-1}+u_{t}$

The log of the home-market share price, $P_{t}^{h}$, follows a random walk and introduces the innovation or random-walk component in the intrinsic value of the firm as $v_{t}$ :

$P_{t}^{h}=P_{t-1}^{h}+v_{t}$

The log of the U.S. share price, $P_{t}^{u}$, adjusts to the last observed exchange rate and homemarket price and also includes a random term, $w_{t}$, to reflect any U.S.-based randomness that may be due to tick-size, liquidity orders, or any other idiosyncratic source:

$P_{t}^{u}=E_{t-1}+P_{t-1}^{h}+w_{t}$

The innovations $u_{t}, v_{t}$, and $w_{t}$ are assumed to be both serially and contemporaneously uncorrelated with zero mean.

Though arbitrage would result in the U.S. price closely following the exchangerate-adjusted home market price during the time of day when the two markets overlap, it is not necessary that the two values be equal at every point in time. There should be a noarbitrage band due to transaction costs, and for ADRs, time lags and associated exchange 
rate risk involved in conversions of home-market shares into ADRs or the flow-back

conversions in the opposite direction. ${ }^{6}$ However, the two stock prices, denominated in the same currency, should move closely together over time. If we subtract the log of the U.S. price from the log of the dollar value of a home-market share we have:

$E_{t}+P_{t}^{h}-P_{t}^{u}=E_{t-1}+u_{t}+P_{t-1}^{h}+v_{t}-E_{t-1}-P_{t-1}^{h}-w_{t}=u_{t}+v_{t}-w_{t}$

Since the linear combination of the log exchange rate, log home-market price, and log

U.S. price is stationary, $E_{t}, P_{t}^{h}$, and $P_{t}^{u}$ are cointegrated with cointegrating vector $A^{\prime}=\left[\begin{array}{ll}1 & 1\end{array}-1\right]$. It is easily seen that in the simple model of equations (1)-(3) only the home market innovations $u$ and the exchange rate innovations $v$ determine the long run development of the U.S. price. Both home market price and exchange rate are completely determined by their own innovations, whereas the U.S. market innovations $w$ exert only a transitory effect on the U.S. price and do not influence the home market price and the exchange rate at all. In other words, price discovery for the stock is exclusively taking place in the home market. In our empirical model, however, we allow the innovations of both home market price, exchange rate, and U.S. market price to exert permanent effects on all three price series. However, the magnitude of the permanent effects are allowed to be different and estimated empirically. Note that in the simple model outlined above the permanent effect of an innovation is either 100 percent (innovation $u$ on $E$ and $P^{u}$, respectively and innovation $v$ on $P^{h}$ and $P^{u}$, respectively) or zero (innovation $w$ on all price series).

For the general model employed in our empirical analysis, we maintain the assumption of the existence of one cointegrating relation between $E_{t}, P_{t}^{h}$, and $P_{t}^{u}$ with

\footnotetext{
${ }^{6}$ Miller and Morey (1996) study the price of Glaxo-Wellcome stock during the overlap of trading between London and New York and show that the differences between the ADR and the London price do not exceed the transaction costs that would be associated with arbitrage.
} 
cointegrating vector $A^{\prime}=\left[\begin{array}{lll}1 & 1 & -1\end{array}\right]$. We further assume that the vector $P_{t}=\left(E_{t}, P_{t}^{h}, P_{t}^{u}\right)^{\prime}$ can be represented by a nonstationary vector autoregression of the form:

$P_{t}=\beta+\phi_{1} P_{t-1}+\phi_{2} P_{t-2}+\ldots+\phi_{q} P_{t-q}+\varepsilon_{t}$

where $\varepsilon_{t}$ is zero-mean white noise with covariance matrix $\Omega$. From the Granger

Representation Theorem (Engle and Granger, 1987) we know that if there are

cointegrating relations among the elements of $P$, there exists an error correction representation of the form:

$\Delta P_{t}=\alpha+B Z_{t-1}+\delta_{1} \Delta P_{t-1}+\delta_{2} \Delta P_{t-2}+\ldots+\Delta P_{t-q+1}+\varepsilon_{t}$

where $Z_{t-1}=A^{\prime} P_{t-1}$.

\section{CONTRIBUTIONS TO PRICE DISCOVERY}

In order to estimate the contribution of each market to price discovery, we adapt the method proposed by Hasbrouck (1995), and write the cointegrated system in a vector moving average (VMA) representation:

$\Delta P_{t}=\Psi(L) \varepsilon_{t}=\varepsilon_{t}+\psi_{1} \varepsilon_{t-1}+\psi 2 \varepsilon_{t-2}+\ldots$

Cointegration of the three price series with cointegrating vector $A^{\prime}$ implies that $A^{\prime} \Psi(1)=0$, where $\Psi(1)=I+\psi_{1}+\psi_{2}+\ldots$. The estimation of the $\Psi(1)$ matrix is the cornerstone of the analysis since this matrix contains information about the magnitude of the permanent effect that each of the innovations exerts on the long run dynamics of the three prices. The econometric methodology to estimate $\Psi(1)$ involves three steps. First, the Schwarz information criterion (SIC) is employed to identify the appropriate lag length in equation (6). In the second step we estimate a VEC model with the identified lag length, which is then used in a dynamic simulation to estimate the VMA parameters in 
(7) and the elements of the $\Psi(1)$ matrix. ${ }^{7}$ Once $\Psi(1)$ is estimated, we can infer the share of information associated with innovations to each market by using a method similar to Hasbrouck (1995). ${ }^{8}$ In contrast to Hasbrouck's analysis, however, our model contains two common trends that can be naturally associated with the efficient exchange rate and the efficient stock price. Hasbrouck's price discovery study of inner-U.S. markets implies one common trend (the efficient stock price) and N-1 cointegrating relations (with $\mathrm{N}$ the number of parallel markets), whereas in our model of international price discovery there is room only for one cointegrating vector.

From Stock and Watson's (1988) common trends representation of a cointegrated system it can be seen that the permanent impact of innovations on the three asset prices is given by the vector $\Psi(1) \varepsilon_{t}$. It is useful to write the components of this vector explicitly as: $\Psi(1) \varepsilon_{t}=\left[\begin{array}{lll}\psi_{11} & \psi_{12} & \psi_{13} \\ \psi_{21} & \psi_{22} & \psi_{23} \\ \psi_{31} & \psi_{32} & \psi_{33}\end{array}\right]\left[\begin{array}{c}\varepsilon_{t}^{e} \\ \varepsilon_{t}^{h} \\ \varepsilon_{t}^{u}\end{array}\right]$.

For example, with the elements in $P_{t}$ being ordered as $E_{t}, P_{t}^{h}$, and $P_{t}^{u}$, the first row of $\Psi(1) \varepsilon_{t}, \psi_{11} \varepsilon_{t}^{e}+\psi_{12} \varepsilon_{t}^{h}+\psi_{13} \varepsilon_{t}^{u}$, gives the long-run component of the innovations that is permanently impounded in the exchange rate. The permanent impact of a one unit innovation in price $j$ on price $i$ is given by $\psi_{i j}$. For instance, $\psi_{12}$ is the long-run impact of a one-unit innovation in the home-market price on the exchange rate random walk. Given our prior beliefs regarding international price discovery, we expect the $\Psi(1)$

\footnotetext{
${ }^{7}$ See Hamilton (1994) p. 318-323 for a discussion of this method.

${ }^{8}$ An alternative method for inferring price discovery follows Gonzalo and Granger's (1995) common factor approach. In a special issue of the Journal of Financial Markets, papers by Lehmann (2002), Baillie, Booth, Tse, and Zabotina (2002), DeJong (2002), Hasbrouck (2002), and Harris, McInish, and Wood (2002), provide a detailed analysis of the two approaches. One important difference arises in the possible imprecision of the information shares approach if there exists substantive cross-correlation across markets. In our application, the residual correlations across markets are so small that imprecision is not a practical issue.
} 
matrix to have a specific form. In particular, we expect: $\psi_{12}=\psi_{13}=0, \psi_{22}=\psi_{32}$,

and $\psi_{23}=\psi_{33}$. Intuitively, $\psi_{12}$ and $\psi_{13}$ equaling zero means that the exchange rate is unaffected by home and U.S. market innovations. Furthermore, the assumed symmetric response to innovations coming from the home and the U.S. market (implied by $\psi_{22}=\psi_{32}$ and $\psi_{23}=\psi_{33}$ ) follows from the restrictions imposed by cointegration, i.e., $A^{\prime} \Psi(1)=0$ and a cointegrating vector of $A^{\prime}=[11-1]$. We have no prior belief with regard to $\psi_{21}$ and $\psi_{31}$, as the two stock prices may have different responses to exchange rate innovations. The estimation results reported below will provide an empirical test of these priors.

To find the information shares attributable to each market, we decompose the variance of long-run impacts $\operatorname{var}\left(\psi_{i 1} \varepsilon_{t}^{e}+\psi_{i 2} \varepsilon_{t}^{h}+\psi_{i 3} \varepsilon_{t}^{u}\right), i=1,2,3$. These variances can be found on the diagonal of the matrix $\psi \Omega \psi^{\prime}$. The information shares are obtained by a decomposition of each of the three variances into the contributions of each market. In case of contemporaneous correlation among the innovations, it is not possible to identify an independent information share for each asset without further restrictions. To circumvent this problem, we follow the standard approach by using the Cholesky factorization of $\Omega$. This provides a lower triangular matrix $C$, where $\Omega=C^{\prime} C$. The Cholesky factorization is creating an orthogonalization by which one could, for example, first isolate the impact of the exchange rate innovation, then the home-market innovation conditioned on the exchange rate innovation, and then the U.S. innovation, conditioned on both of the other markets. In this recursive setting, one may think of the orthogonalized innovation in the U.S. market as being the residual of a regression of the 
U.S. innovation on the innovations in the exchange rate and home-market price. ${ }^{9}$ With a given ordering of markets, one now may compute the information share of market $j$ with respect to price series $i, S_{i j}$, as:

$$
S_{i j}=\left([\psi C]_{i j}\right)^{2} /\left(\psi \Omega \psi^{\prime}\right)_{i i}
$$

This normalization guarantees that the information shares sum to unity for each price series. The Cholesky factorization will result in providing an upper bound on the share for the market ordered first and a lower bound for the share of the market ordered last. Hence, the resulting information shares will depend upon a specific ordering of the markets, and it is important to check that the qualitative results are robust across alternative orderings. There are a couple of ways in which this issue may be addressed. We could appeal to directed acyclic graph analysis as discussed in Swanson and Granger (1997) to motivate a particular ordering of the variables (which would support a choice of the order we actually use: exchange rate, home-market price, and U.S. price). However, given our high frequency sample, we will demonstrate in our empirical application that the estimated upper and lower bounds for the information shares lie in a very tight range regardless of the ordering so that the issue is relatively unimportant in our case.

\section{DATA AND ESTIMATION RESULTS}

\subsection{Data and Informal Evidence}

We study the relationship between U.S. and German trading over the common trading time overlap each day for the period August 1 to October 31, 1999. The overlap between Frankfurt and New York trading is from 14:30 to 16:00 GMT (or 9:30-11:00 New York time) until September 20, 1999. On this day, the XETRA opening and closing hours were shifted forward by 30 minutes so that the overlap is from 14:30 to 16:30 GMT

\footnotetext{
${ }^{9}$ Hamilton, p. 321-323 has a good discussion of this issue.
} 
for the remainder of the sample. The exchange rate data are tick-by-tick quotes on the dollar price of the euro as reported on the Reuters indicative quoting screen. The data were obtained from Olsen \& Associates, Zurich. See Danielsson and Payne (2002) for an instructive discussion of indicative exchange rate quotes compared to the quotes on an electronic brokerage. Since the indicative quotes are from individual dealers but the brokerage reports the inside spread (the best bid and ask across all contributing dealers), indicative quotes tend to be more volatile and exhibit higher negative autocorrelation than the best bid and ask quotes from the brokerage. However, quotes from the brokerage are not public information and only indicative quotes are available for our sample. The NYSE quote data are taken from the TAQ data set available from the NYSE. The XETRA quote data are proprietary data provided by the Frankfurt Stock Exchange for this study. Both quote series represent firm quotes at which trades may occur. Table 1 lists summary statistics for each firm and each market. The first two columns provide average bid and ask prices. XETRA quotes are in euro while NYSE quotes are in dollars. The dollar price of the euro was greater than 1 during this period, with a mean of 1.0607 for the bid price, so dollar prices exceed euro prices on the same firm. The SAP ADR represents 1/12 of a share of SAP stock as issued in Germany. In Table 1 and the empirical work that follows, the NYSE prices are multiplied by 12 to be comparable to the home-market shares. The third column shows that XETRA quoting is more intense than NYSE. XETRA quotes range from 3.4 times the NYSE quotes for DCX to 3.9 times the NYSE quotes for DT. Number of shares traded is also higher on XETRA than for the NYSE. The fourth column shows the average daily trading volume in each market and it is seen that the ratio of XETRA volume to NYSE volume ranges from 3.0 for SAP to 20.5 for DT. The last column reports the average daily turnover as measured in euro for XETRA and dollars for the NYSE. In German trading, DCX generates the 
highest volume, followed by DT and then SAP. Analyzing the share of volume we see that the NYSE share is largest for SAP, followed by DCX and DT.

<Table 1 goes here>

Figure 1 plots the stock prices and the exchange rate, all measured as the average of bid and ask prices, over the 3-month period we study. The difference between the two prices reflects the exchange rate, which is seen in the final graph to move in a fairly narrow range over the sample period. The actual dollar/euro exchange rate traded within a range of 1.0355 to 1.0889 over the August - October period studied. The fact that the exchange rate was close to 1 over the period results in the XETRA euro price and the NYSE dollar price moving closely together over time.

\section{<Figure 1 goes here $>$}

The volume and turnover data presented in Table 1 tend to confirm the notion that XETRA provides the primary market and U.S. trading is in the derivative asset. Additional informal evidence may be seen in plots of the quoting intensity of each market. Figure 2 presents plots of the average number of quote updates per second for each 5- minute interval over the trading day. The period of overlap between New York and Frankfurt is the peak period of activity during the day. Note how quoting intensity rises in Frankfurt with the New York opening and how quoting intensity falls in New York with the Frankfurt close. This effect seems most pronounced for DT and we shall see below how the information shares indicate that DT seems much more a German firm than an international firm. The spike in Frankfurt quoting that occurs at 13:30 is associated with the close of floor trading. Overall, Figure 2 is consistent with the New York trading being derived from Frankfurt, but it is also suggestive of synergies between the two markets as quoting intensity in Frankfurt rises when New York opens. ${ }^{10}$

\section{<Figure 2 goes here>}

\footnotetext{
${ }^{10}$ An examination of similar plots for trades instead of quotes reveals the same synergies existing between Frankfurt and New York
} 


\subsection{Econometric Model Specification and Estimation}

The informal evidence presented in Table 1 and Figure 2 is useful and provocative, but is only suggestive of the interdependencies between the markets. We now turn to the formal econometric evidence regarding the relationship between U.S. and home-market trading. First, we discuss additional issues related to data and sampling and then we develop the estimates in line with the discussion in Sections III and IV.

All asset price series are in logarithms of the average of the bid and ask prices. We use the midpoint of the quotes rather than the bid or ask as our basic unit of observation for two reasons. First, this is the most frequent methodology used in the literature. Second, using midpoints minimizes the possibility that quotes are being revised just on one side of the market or the other to reflect positions. It is unlikely that the choice of midpoint versus bid or ask prices will have any substantive effect on the results. The asset prices were sampled at 10-second intervals to assemble the basic data set. The choice of sampling interval was made with the issue of contemporaneous correlation in mind. There can be one-way causality existing among variables at a high sampling frequency that dissolves into contemporaneous correlation at higher levels of temporal aggregation. ${ }^{11}$ We examined the correlations among the residuals of our threeequation VEC system over alternative sampling frequencies and chose 10 seconds as being suitable relative to lower frequencies like 1 minute, as the 1 minute frequency yielded much more evidence of significant contemporaneous correlation. At sampling frequencies higher than 10 seconds there was no gain in terms of reducing significant contemporaneous correlations, but there is a tradeoff with issues such as nonsynchronous quoting or other sources of microstructure "noise" that makes 10 seconds preferable. An additional sampling issue is with regard to overnight returns and lags.

\footnotetext{
${ }^{11}$ See Granger (1988) for discussion of related issues.
} 
We created a data set that started each day with observations on the dependent variables and lags so that no overnight returns were used and no lags reached back to prior days. For instance, if the model calls for 3 lags in the VEC, the dependent variable begins with the fourth observation of each day. The initial observation each day for each stock was determined by the first 10 -second interval following the NYSE open containing a quote in both markets.

Augmented Dickey-Fuller tests revealed unit roots in the log of each asset price and the variables were identified as being I(1). Johansen cointegration tests were performed and the results clearly support the hypothesis of one cointegrating vector among the 3 variables (see Table 2). The next step is to estimate the VEC equation (7). The choice of lag length was determined by the Schwarz Information Criterion (SIC). We started with 18 lags, which is 3 minutes in a sample with observations at 10 -second intervals. Then, holding the number of observations constant, we estimated the VEC at each shorter lag length down to 1 lag to determine the lag structure that minimized the SIC. This revealed 3 lags as optimal for SAP and DT and 4 lags as optimal for DCX. The cointegrating relations of the estimated VECs are reported in Table 2. With the variables ordered as exchange rate, home-market price, and U.S. price, the estimated cointegrating vectors are close to the vector $A^{\prime}=\left[\begin{array}{lll}1 & 1 & -1\end{array}\right]$ indicated by theory. For each security, summary statistics are given on the order of cointegration in Table $2 .^{12}$ In all 3 cases, the data support one cointegrating vector.

\section{<Table 2 goes here $>$}

The estimation precision is assessed by employing the bootstrap method suggested by Li and Maddala (1997). In order not to distort the dynamic properties of the cointegrated system we choose to bootstrap from the residuals of our estimated VEC

\footnotetext{
${ }^{12}$ See Johansen (1991) for discussion of the test statistics.
} 
models rather than from the actual data. ${ }^{13}$ More precisely, the estimated residuals are resampled by drawing observations randomly with replacement and then building a new vector of observations on the data from the innovations and the lagged values of the dependent variables. From the new set of observations, parameters are re-estimated. This process is repeated 1,000 times to generate the empirical distributions for the parameters of interest. The bootstrap procedure offers the chance to obtain parameter standard errors (and in fact estimates of the whole distribution) when they are not available analytically. We thus overcome the drawback that the precision regarding estimates of the long run impact matrix and the information shares cannot be assessed analytically. All standard errors reported in tables 3 (long run impacts) and 4 (information shares) as well as the density estimates of the information shares in figure 3 are based on the bootstrap samples. ${ }^{14}$

By a dynamic simulation of the VECMs we find the VMA parameter matrices in equation (8) and, by summing up, the estimates of the $\Psi(1)$ matrix. As a byproduct, this procedure also enables us to plot impulse response functions (IRFs) which illustrate the impact of a one-unit innovation in the XETRA price, the NYSE price, and the exchange rate. The values to which the IRFs converge are the respective elements of the $\Psi(1)$ matrix. IRF plots of the functions are given in Figure 3 and estimates of the $\Psi(1)$ matrix are reported in Table 3. Focusing first on the NYSE innovations, one can see that there is a larger impact on XETRA prices for DCX and SAP than for DTE. In addition, there is no apparent effect on the exchange rate. Similarly, a shock to the XETRA price has no effect on the exchange rate, but a considerable effect on the NYSE price. Finally, exchange rate innovations are seen to have a large impact on the NYSE price but a very

\footnotetext{
${ }^{13}$ Given the dynamic structure of the model, bootstrapping the dependent variables would distort the true relationships when lagged dependent variables appear on the right-hand-side of the equation. See Sapp (2000) for a similar bootstrap application to high-frequency exchange rate data.

${ }^{14}$ Asymptotic inference on the long-run impact matrix and the information shares is provided by Paruolo (1997a, 1997b).
} 
small effect on the XETRA price. The effects just detailed anticipate the price-discovery findings to be reported below. In terms of the time required for the system to converge to a new equilibrium, the impulse responses are plotted for units representing 10-second intervals. While results differ somewhat across the various plots in Figure 3, it appears that convergence to the new equilibrium occurs within about 200 intervals, or 33 minutes, following a 1-unit innovation in the various prices.

\section{<Figure 3 goes here >}

The estimates of the $\Psi(1)$ matrices meet our prior expectations as discussed in the previous section: the exchange rate appears to be unaffected by innovations in the stock prices (for instance, the DCX impact of a unit shock to the XETRA price on the exchange rate of -0.005 with a standard error of 0.011 ); the long-run impact of a shock to the XETRA price is about the same on both XETRA and NYSE prices (note the DCX impacts of a unit shock to the XETRA price equal to 0.822 and 0.818 on XETRA and NYSE prices, respectively); and the long-run impact of a shock to the NYSE price is about the same on both XETRA and NYSE prices (DCX impacts of 0.250 and 0.261 for NYSE shock effects on XETRA and NYSE prices, respectively). In addition, Table 3 reports estimates of parameters for which we had no prior beliefs: the long-run impact of a shock to the XETRA price is greater than the long-run impact of a shock to the NYSE price (compare 0.822 to 0.250 for the DCX XETRA price) and shocks to the exchange rate have a greater impact on the NYSE price than the XETRA price (compare 0.435 to 0.132 for DCX). The greater impact of XETRA prices compared to NYSE prices is consistent with a view that price is discovered in Frankfurt and then New York follows with the derivative market.

\section{$<$ Table 3 goes here $>$}

The fact that the NYSE price appears to accommodate most of the adjustment to an exchange rate shock while the XETRA price is relatively unaffected by such shocks is 
important new evidence on how international equity prices evolve. One might think that, given a shift in the exchange rate, both prices would tend to adjust to a new equilibrium defined by the new exchange rate. For instance, if the dollar depreciates against the euro, we might expect arbitrage forces to result in a rise in the NYSE price and a simultaneous fall in the XETRA price in order for the "law of one price" to hold in the international equity market. Instead, the evidence indicates that almost all of the adjustment to a new exchange rate comes through changes in the NYSE price. There is a small and statistically significant negative effect of the exchange rate innovation on the XETRA price that is roughly the same magnitude for DCX and SAP but much smaller for DT. However, the NYSE effect is about 3 times the XETRA effect for DCX and SAP and about 12 times the XETRA effect in the case of DT. ${ }^{15}$ The fact that the NYSE price does most of the adjustment to an exchange rate shock is additional evidence that the ADR is priced as the derivative asset. Given the home-market price, a change in the exchange rate requires a change in the NYSE price in order to follow the XETRA price. In order to prevent arbitrage opportunities, it is no surprise that there is a very quick adjustment in the stock prices following an exchange rate change. This dynamic pattern of adjustment to an exchange rate change across international equity markets would be lost in an analysis at a low time series frequency.

\subsection{Information Shares}

As explained above, the triangularization of the innovation variance-covariance matrix results in an upper bound on the estimated information share for the variable that

\footnotetext{
${ }^{15}$ The exchange rate evidence is also suggestive that our overall results are not driven by the fact that there is more frequent quoting on XETRA than the NYSE. It does not appear to be the case that XETRA seems to be the "first mover" just because they have more frequent quotes. The NYSE quotes do most of the adjusting to the exchange rate while XETRA quotes appear to be relatively unaffected by exchange rate changes. The differences in our estimates across firms (even though all three have about the same ratios of XETRA to NYSE quotes) is corollary evidence that the results may reflect real economic phenomena and are not just an artifact of quote frequency.
} 
comes first in the ordering and a lower bound on the information share for the variable that comes last in the ordering. We will later address this issue by estimating the upper and lower bounds of information shares. First, an ordering of exchange rate, homemarket price, and U.S. price is used to estimate the information shares. We use this order in computing the information shares reported in Table 4.

$<$ Table 4 goes here $>$

Table 4 contains estimates and standard errors of information shares. For instance, consider the first row of information shares for DCX. The exchange rate innovations account for essentially all price discovery in the exchange rate with the stock prices contributing essentially nothing. This is consistent with the exchange rate being exogenous with respect to the two stock prices. The same pattern is seen for the other two stocks as well. Figure 3 contains estimates of the kernel densities associated with the information shares. The figure provides a more detailed look at the differences across the firms than the standard errors reported in Table 4.

\section{$<$ Figure 3 goes here $>$}

Analyzing the information shares related to the XETRA prices, we find that the exchange rate innovations contribute less than 1 percent for all three firms. The XETRA price innovations are shown to be most important with information shares ranging from 0.991 for DT to 0.798 for SAP. The NYSE innovations have an information share of approximately zero for DT, about 9 percent for DCX, and about 20 percent for SAP.

The information shares related to NYSE prices indicate that the exchange rate accounts for shares ranging from about 5 percent for DT to about 7 percent for DCX. XETRA price innovations have the largest information share of about 84 percent for DCX, 94 percent for DT, and 75 percent for SAP. The NYSE price innovations account for an information share of about zero for DT, 9 percent for DCX, and 19 percent for SAP. Note that the estimation precision is high as indicated by the small standard errors. 
The top two graphs of Figure 4 emphasize the result that the exchange rate innovations have an effect on NYSE prices that is markedly different than the effect on the XETRA prices. If one superimposed the XETRA figure on the NYSE, not even the extreme tails would overlap. On the other hand, it is seen in the four lower figures that the effects of XETRA price innovations and NYSE price innovations are similar for stocks in both trading locations. The kernel densities look quite similar for XETRA innovation effects on XETRA and NYSE prices and NYSE innovation effects on XETRA and NYSE prices.

An overview of the results reported in Table 4 and Figure 3 offers a clear interpretation of the findings: a) the exchange rate is exogenous with respect to the stock prices; b) exchange rate innovations are more important in understanding the evolution of NYSE prices than XETRA prices; and c) most of the fundamental or random walk component of the value of the 3 firms is determined in Frankfurt.

There are striking differences across the three firms, especially between the DT and SAP results. The XETRA price innovation share is above 99 percent for the XETRA price of DT. The same information share for SAP is about 75 percent. There is almost a 20 percent information share for the NYSE innovation in both the XETRA and NYSE prices for SAP. Why does DT have such a large information share for XETRA relative to SAP and DCX? In contrast to DCX and SAP, DT appears to be more of a German firm than a multinational firm. This is borne out in the revenue data as U.S.-based revenue accounts for less than 1 percent of DT revenue, a little more than 50 percent of DCX revenue, and a little less than 50 percent of SAP revenue. ${ }^{16}$ Even more descriptive of the differences between the multinational nature of SAP shares relative to DT is the U.S. versus non-U.S. location of mutual fund holders of each stock. The shares of the NYSE

\footnotetext{
${ }^{16}$ An examination of each firm's web homepage indicated the following recent data: DCX, total revenue in the $3^{\text {rd }}$ quarter of 1999 was 36.3 billion euro with 19.3 billion euro from the U.S.; DT, total revenue in 1999 was 35.5 billion euro with 161 million euro from the U.S.; SAP, total revenue in the $3^{\text {rd }}$ quarter of 1999 was 1.1 billion euro with 492 million euro from the U.S.
} 
traded stocks held by U.S. versus non-U.S. mutual funds in January, 2001 are: DCX, 9,152,343/132,084,720; DT, 693,933/24,173,898; and SAP, 7,969,826/958,013. ${ }^{17}$ U.S. mutual funds own more than 8 times as many SAP ADRs as non-U.S. funds. However, only 3 percent of DT ADRs are owned by U.S. mutual funds. The largest owners of SAP tend to be large U.S. institutions (the top 5 being INVESCO Funds Group, Inc., INVESCO Capital Management, Inc., MFS Investment Management, Smith Barney Asset Management, and Kayne Anderson Rudnick Investment Management, LLC) while the largest owners of DT tend to be non-U.S. funds (the top 5 includes Brandes Investment Partners, LP, Frankfurt Trust, Union Bank of Switzerland-Asset Management, Citadel Investment Management, LP, and UBS Warburg). It is clear that SAP has a much stronger following in the United States than DT. DCX, on the other hand, lies between the results found for DT and SAP. While DCX and SAP both have similar U.S. revenue shares, their ownership patterns are quite different. DCX ownership is more similar to DT with U.S. mutual funds holding only about 7 percent of the shares. So DCX lies in between SAP and DT in terms of the strength of its U.S. following. Beyond the obvious differences in terms of the geographic distribution of ownership, there may be some additional factors that help explain the fact that SAP has a larger share of price discovery for the NYSE than DT or DCX. First, SAP is considered a "new economy" stock and the U.S. market focus on those firms may account for the larger information share of the NYSE. Second, SAP's biggest rivals are U.S. firms. So U.S. news may be more relevant for SAP than DCX, who has major rivals in Europe and Asia, or DT, who essentially does business in Europe only.

The ordering of variables underlying Table 4 was motivated by our priors on the likely recursive ordering of the contemporaneous correlation. However, one can further explore the sensitivity of results over the alternative possible orderings. We do so in

\footnotetext{
${ }^{17}$ Mutual fund ownership is listed on the J.P. Morgan ADR web site: www.adr.com.
} 
order to demonstrate that the bounds for information shares are quite small. By permuting the order of variables in the Cholesky decomposition, we find the bounds for information shares given in Table 5. In many cases, the bounds are so tight that the upper and lower values round to the same 3 decimal places. In other cases, there is less than 1 percentage point difference. Given the tight bounds that exist over alternative orderings, it is clear that the information shares and associated inferences are unaffected in any substantive manner by the ordering of variables.

\section{$<$ Table 5 goes here $>$}

As a final robustness check, we re-estimated the system using one-minute sampling intervals instead of the 10 -second intervals employed above. The results change little. The most notable difference is for DCX. At the lower one-minute frequency there is a larger (smaller) information share for NYSE (XETRA) innovations on prices in both markets and a larger (smaller) impact of exchange rate innovations on XETRA (NYSE) prices. We conjecture that this has to do with DCX being a globally registered share with a narrower no-arbitrage band than in the case of the ADRs. Consider the effects of an exchange rate shock. The NYSE price adjusts quickly to restore the law of one price while the XETRA price moves very little. This is as found at the 10 -second frequency. However at a lower frequency, the true relationships become blurred as the NYSE information share is overstated as it includes both the effects of NYSE price shocks as well as the exchange rate shocks to which the NYSE price has already adjusted.

\subsection{Simulation of Bivariate and Trivariate Models}

It is important to emphasize that information shares may be sensitive to the methodology chosen with respect to the exchange rate. Prior studies have used the exchange rate to convert one stock price into the same currency units as the other and 
then estimate a two-variable, or bivariate, system. We allow the exchange rate to enter the analysis separately and estimate a three-variable, or trivariate, system. To explore the sensitivity of information shares to model specification, a simulation study is conducted. Specifically, a data generating process (DGP) is simulated to find the information shares of NYSE innovations with respect to the XETRA price and XETRA innovations with respect to the NYSE price. The variance of the exchange rate innovations is allowed to take five different values. Then the trivariate model, as put forward in this paper, is compared to the bivariate model. The latter is estimated both in terms of the NYSE price converted to euros and the XETRA price converted to dollars. The exact parameterization of the model is given in Table 6. We generate 1,000 datasets of 40,000 observations each using the model specified in Table 6 for each of the exchange rate variance values. Table 6 reports the average information shares over the 1,000 replications for each DGP.

< Table 6 goes here $>$

The trivariate model reports exchange rate information shares for home and U.S. stock prices. As expected, the greater the volatility of the exchange rate, the greater the exchange rate information shares. Of greater interest, however, is the stock price information shares. The true DGP implies that the information shares associated with each stock price should be equal, or their ratio should equal 1. As shown in Table 6, this is basically the result found in the trivariate case. However, the bivariate models reveal that the greater the exchange rate variance, the greater the information share of the stock market incorporating the exchange rate and the smaller the information share of the other market. For instance, with an exchange rate variance of 2, if the U.S. price is converted to euros, then the U.S. information share is 0.821 while the home information share is 0.179. But if the home price is converted to dollars, then the results are just reversed. The simulations clearly reveal that the bivariate approach can be quite misleading with a 
bias towards overstating the information share of the market whose price is converted into the foreign currency. The more volatile are exchange rates, the greater the bias.

\section{SUMMARY AND CONCLUSIONS}

We now return to the initial questions that motivated this study: where does price discovery occur for internationally-traded firms and how do international stock prices adjust to an exchange rate shock? Our approach to answering these questions involves an analysis of the high-frequency quotes on three blue-chip German firms during the daily overlap of trading in Frankfurt on XETRA and New York on the NYSE. While the results support the notion that price discovery occurs largely in the home market, results differ across our three firms. In order of the information shares attributed to Frankfurt trading in explaining XETRA (NYSE) price innovations we have DT, with 99 (94) percent; DCX, with 91 (84) percent; and SAP, with 80 (75) percent. The high share for DT is likely a result of the fact that almost all DT revenue is earned in Germany and DT ADR ownership is concentrated outside the U.S. DCX and SAP both have substantial U.S. revenue sources and SAP ADR ownership is concentrated inside the U.S. It makes intuitive sense that multinational firms would have more room for international price discovery than firms that are essentially operating only in their home market.

An additional question of interest related to the first question is: how do international stock prices adjust to an exchange rate shock? We find that the New York prices bear almost all of the adjustment to exchange rate changes. For each of our firms, the information shares attributed to the exchange rate in explaining XETRA prices are approximately zero. For NYSE prices, the exchange rate innovations have an information share of at least 5 percent. Thus, the NYSE investor is subject to exchange 
rate risk in that prices incorporate another source of uncertainty beyond the value of the firm itself and this is not the case for the home market investor.

Simulation results indicate the potential importance of estimating a trivariate system with an independent role for the exchange rate rather then a bivariate system where the exchange rate is used to convert one price into the same currency as the other price. The bivariate system suffers from a bias towards overstating the information share of the market whose price is converted into foreign currency. The greater the exchange rate volatility, the greater the bias. In the case of low exchange rate volatility, as in our sample, the bias should not be large. However, without estimating the trivariate system, it would not be possible to reveal the dependence of NYSE prices on exchange rate shocks and the independence of XETRA prices.

The evidence suggests a structure of the international equity market that has the home-market largely determining the random walk component of the international value of a firm along with an independent role for exchange rate shocks to affect prices in the derivative markets. This is not to say that the NYSE does not contribute to price discovery in the case of New York trading in foreign firms. In fact, we find that for SAP the information share of the NYSE in explaining XETRA and NYSE price innovations is about 20 percent. So while there may be some role for U.S. market price discovery, the evidence is strongly supportive of prices largely being determined in the home market. 


\section{REFERENCES}

Baillie, R. T., G. G. Booth, Y. Tse, and T. Zabotina, 2002, Price discovery and common factor models, Journal of Financial Markets 5, 309-321.

Bailey, W., K. Chan, and Y.P. Chung, 2000, Depositary receipts, country funds, and the peso crash: the intraday evidence, Journal of Finance 55, 2693-2717.

Chen, S.X., 1999, Beta kernel estimators for density functions, Computational Statistics and Data Analysis 31, 131-145.

Danielsson, J., and R. Payne, 2002, Real trading patterns and prices in spot foreign exchange markets, Journal of International Money and Finance 21, 203-222.

DeJong, F., 2002, Measures of the contribution to price discovery: a comparison, Journal of Financial Markets 5,323-327.

Ding, D.K., F.H. deB. Harris, S.T. Lau, and T.H. McInish, 1999, An investigation of price discovery in informationally-linked markets: equity trading in Malaysia and Singapore, Journal of Multinational Financial Management 9, 317-329.

Engle, R.F., and C.W.J. Granger, 1987, Co-integration and error correction: representation, estimation, and testing, Econometrica, 55, 251-276.

Eun, C.S., and S. Sabherwal, 2003, Cross-border listings and price discovery: evidence from U.S.-listed Canadian stocks, Journal of Finance 58, 549-576.

Gonzalo, J., and C. Granger, 1995, Estimation of common long-memory components in cointegrated systems, Journal of Business and Economic Statistics 13, 27-35.

Granger, C.W.J., 1988, Some recent developments in a concept of causality, Journal of Econometrics 39, 199-211.

Hamilton, J.D., 1994, Time Series Analysis (Princeton University Press).

Harris, F.H. deB., T.H. McInish, and R.A. Wood, 2002, Common factor components versus information shares: a reply, Journal of Financial Markets 5, 341-348. 
Harris, F.H. deB., T.H. McInish, and R.A. Wood. 2001, DCX trading in New York and Frankfurt: insights from intraday data, University of Memphis Working Paper, June.

Hasbrouck, J., 1995, One security, many markets: determining the contributions to price discovery, The Journal of Finance 50,1175-1199.

Hasbrouck, J., 2002, Stalking the 'efficient price' in market microstructure specifications: an overview, Journal of Financial Markets 5, 329-339.

Johansen, S., 1991, Estimation and hypothesis testing of cointegration vectors in Gaussian vector autoregressive models, Econometrica 59, 1551-80.

Karolyi, G.A., 2003, DaimlerChrysler AG, the first truly global share, Journal of Corporate Finance 9, 409-430.

Karolyi, G.A. and R.M. Stulz, 1996, Why do markets move together? An investigation of U.S.-Japan stock return comovements, Journal of Finance 51,951-986.

Kato, K., S. Linn, and J. Schallheim, 1990, Are there arbitrage opportunities in the market for American Depository Receipts? Journal of International Financial Markets, Institutions, and Money 1, 73-89.

Kim, M., A.C. Szakmary, and I. Mathur, 2000, Price transmission dynamics between ADRs and their underlying foreign securities, Journal of Banking and Finance 24, 1359-1382.

Lau, S.T., and J.D. Diltz, 1994, Stock returns and the transfer of information between the New York and Tokyo stock exchanges, Journal of International Money and Finance 13, 211-222.

Lehmann, B. N., 2002, Some desiderata for the measurement of price discovery across markets, Journal of Financial Markets 5, 259-276.

Li, H., and G.S. Maddala, 1997, Bootstrapping cointegrating regressions.” Journal of Econometrics 80, 297-318. 
Lieberman, O, U. Ben-Zion, and S. Hauser, 1999, A characterizaation of the price behavior of international dual stocks: an error correction approach, Journal of International Money and Finance 18, 289-304.

Melvin, M., forthcoming, A stock market boom during a financial crisis? ADRs and capital outflows in Argentina, Economics Letters.

Miller, D.P. and M.R. Morey, 1996, The intraday pricing behavior of international dually listed securities, Journal of International Financial Markets, Institutions, and Money 6, 79-89.

Paruolo, P., 1997a, Asymptotic inference on the moving average impact matrix in cointegrated VAR systems, Econometric Theory 13, 79-118.

Paruolo, P., 1997b, Standard errors for the long run variance matrix, Econometric Theory $14,152-153$.

Sapp, S., forthcoming, Price Leadership in the Spot Foreign Exchange Market, Journal of Financial and Quantitative Analysis.

Shleifer, A. and R.W. Vishny, 1997, The limits of arbitrage, Journal of Finance 52, 3555.

Silverman, B.W., 1986, Density estimation for statistics and data analysis (Chapman \& Hall, London).

Stock, J.H., and M.W. Watson., 1988, Testing for common trends, Journal of the American Statistical Association 83, 1097-1107.

Swanson, N.R., and C.W.J. Granger, 1997, Impulse response functions based on a causal approach to residual orthogonalization in vector autoregressions, Journal of the American Statistical Association 92, 357-367.

Theissen, Erik, 2002, Price discovery in floor and screen trading systems, Journal of Empirical Finance 9, 455-474.

Wang, S.S., O.M. Rui, and M. Firth, 2002, Return and volatility behavior of dually- 
traded stocks: the case of Hong Kong, Journal of International Money and Finance 21, 265-293.

Watson, M.W., 1994, Vector autoregression and cointegration, in R.F. Engle and D.L. McFadden, Handbook of Econometrics, Volume IV (Elsevier Science, Amsterdam) 2844-2915. 


\section{Table 1}

\section{Descriptive Statistics for Firms and Markets}

Summary statistics are reported for three firms: DaimlerChrysler (DCX), Deutsche Telekom (DT), and SAP. Trading in the U.S. occurs on the NYSE and trading in Germany occurs on the XETRA system. The data are for the period of trading overlap each day: 14:30-16:00 (or 16:30 from September 20, 1999) over the period from August 1 to October 31,1999. XETRA prices are quoted in euro and NYSE prices are quoted in dollars (the mean bid quote for the exchange rate over the sample period was 1.0607 dollars per euro). DCX and DT shares in the U.S. trade at a 1 to 1 ratio against German shares. SAP shares in the U.S. trade at a 12 to 1 ratio against the German shares, but the table adjusts the NYSE prices and volume by a factor of 12 to make the SAP numbers for each market comparable.

\begin{tabular}{|c|c|c|c|c|}
\hline $\begin{array}{l}\text { Avg. bid } \\
\text { price }\end{array}$ & $\begin{array}{l}\text { Avg. ask } \\
\text { price }\end{array}$ & $\begin{array}{l}\text { Avg. daily no. } \\
\text { of quotes }\end{array}$ & $\begin{array}{l}\text { Avg. daily } \\
\text { trading volume }\end{array}$ & $\begin{array}{l}\text { Avg. daily } \\
\text { turnover }\end{array}$ \\
\hline
\end{tabular}

$\underline{\mathrm{DCX}}$

69.72

69.79

731

794,523

$55,478,987$

NYSE

73.80

73.96

215

203,909

$15,102,534$

$\underline{\mathrm{DT}}$

40.60

40.67

593

$1,024,785$

$41,579,511$

NYSE

42.97

43.14

151

50,075

$2,142,359$

$\underline{\text { SAP }}$

XETRA

402.00

402.70

563

92,917

$37,657,635$

NYSE

429.24

430.92

162

30,749

$13,388,669$ 


\section{Table 2}

\section{VEC Estimation Results}

Vector error correction models are estimated for each firm. The form of equation is:

$$
\Delta P_{t}=\alpha+B Z_{t-1}+\delta_{1} \Delta P_{t-1}+\delta_{2} \Delta P_{t-2}+\ldots+\Delta P_{t-q+1}+\varepsilon_{t}
$$

where $\Delta P_{t}$ contains the change in the logs of the exchange rate, the home-market price, and the U.S. price; $Z_{t-1}$ is the lagged log-levels of each variable in the cointegrating equation estimated by the Johansen method. The table reports the cointegating vector that applies to $Z$. $\alpha, B$, and $\delta$ are coefficients to be estimated and are not reported to conserve space. The bootstrap standard errors are in parentheses. At the bottom of each table is the number of observations for that firm (each day, the time of the first observation is defined by the first quote), the log likelihood associated with the estimated system, and summary statistics associated with the Johansen test for the order of cointegration, where $h=$ number of cointegrating relations, $\mathrm{LR}=$ likelihood ratio statistic, crit. $5 \%$ : critical values of LR statistics taken from Hamilton (1994), pp. 767-768. In each case, the results support 1 cointegrating vector.

Table 2a: DCX Estimation results

\begin{tabular}{lr}
\hline \hline Cointegrating Eq. & \\
$\mathrm{E}$ & $1.00000(0.00000)$ \\
$\mathrm{p}^{\mathrm{h}}$ & $1.01520(0.01683)$ \\
$\mathrm{p}^{\mathrm{u}}$ & $-1.01512(0.01615)$
\end{tabular}

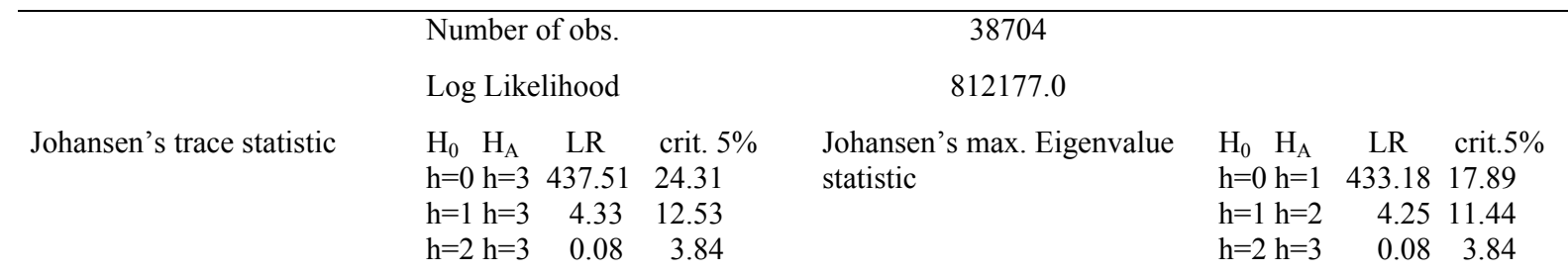

Table 2b: DT Estimation results

\begin{tabular}{lr}
\hline \hline Cointegrating Eq. & \\
$\mathrm{E}$ & $1.00000(0.00000)$ \\
$\mathrm{p}^{\mathrm{h}}$ & $1.01516(0.01754)$ \\
$\mathrm{p}^{\mathrm{u}}$ & $-1.01507(0.01725)$ \\
\hline
\end{tabular}

Number of obs.

Log Likelihood

Johansen's trace statistic

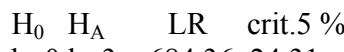
$\mathrm{h}=0 \mathrm{~h}=3 \quad 684.36 \quad 24.31$

$\mathrm{h}=1 \mathrm{~h}=3 \quad 7.07 \quad 12.53$

$\mathrm{h}=2 \mathrm{~h}=3 \quad 0.20 \quad 3.84$

38300

772688.2

Johansen's max. Eigenvalue statistic

$\mathrm{H}_{0} \quad \mathrm{H}_{\mathrm{A}} \quad$ LR $\quad$ crit. $5 \%$ $\mathrm{h}=0 \mathrm{~h}=1 \quad 677.29 \quad 17.89$

$\mathrm{h}=1 \mathrm{~h}=2 \quad 6.86 \quad 11.44$ $\mathrm{h}=2 \mathrm{~h}=3 \quad 0.20 \quad 3.84$

Table 2c: SAP Estimation results

\begin{tabular}{lr}
\hline \hline Cointegrating Eq. & \\
$\mathrm{E}$ & $1.00000(0.00000)$ \\
$\mathrm{p}^{\mathrm{h}}$ & $1.00538(0.02204)$ \\
$\mathrm{p}^{\mathrm{u}}$ & $-1.00523(0.02182)$
\end{tabular}

Number of obs.

Log Likelihood

Johansen's trace statistic
$\begin{array}{llll}\mathrm{H}_{0} & \mathrm{H}_{\mathrm{A}} & \mathrm{LR} \quad \text { crit. } 5 \%\end{array}$ $\mathrm{h}=0 \mathrm{~h}=3 \quad 435.32 \quad 24.31$

$\mathrm{h}=1 \mathrm{~h}=3 \quad 2.12 \quad 12.53$

$\mathrm{h}=2 \mathrm{~h}=3 \quad 0.01 \quad 3.84$

38754

785231.2

Johansen's max. Eigenvalue statistic

$\mathrm{H}_{0} \quad \mathrm{H}_{\mathrm{A}} \quad \mathrm{LR} \quad$ crit. $5 \%$ $\mathrm{h}=0 \mathrm{~h}=1 \quad 433.20 \quad 17.89$

$\mathrm{h}=1 \mathrm{~h}=2 \quad 2.12 \quad 11.44$ $\mathrm{h}=2 \mathrm{~h}=3 \quad 0.01 \quad 3.84$ 


\section{Table 3}

\section{Vector Moving Average Coefficients}

The matrices below are estimates of the $\Psi(1)$ matrix associated with the vector moving average (VMA) models:

$\psi(1)=\left[\begin{array}{lll}\psi_{11} & \psi_{12} & \psi_{13} \\ \psi_{21} & \psi_{22} & \psi_{23} \\ \psi_{31} & \psi_{32} & \psi_{33}\end{array}\right]$

The reported coefficients indicate that the exchange rate appears to be unaffected by innovations in the stock prices. The long-run impact of a shock to the home-market stock price appears to be similar for both XETRA and NYSE prices. Similarly, the long-run impact of a shock to the U.S. stock price appears to be the same for both XETRA and NYSE prices. The long-run impact of a shock to the home-market price is larger than the impact of a shock to the U.S. price in all cases. Shocks to the exchange rate appear to have a larger impact on the NYSE price than the XETRA price. Bootstrap standard errors are in parentheses.

\section{DCX}

$\left[\begin{array}{rrr}0.576(0.010) & -0.005(0.011) & 0.011(0.012) \\ -0.132(0.025) & 0.822(0.031) & 0.250(0.033) \\ 0.435(0.027) & 0.818(0.032) & 0.261(0.034)\end{array}\right]$

DT

$\left[\begin{array}{rrr}0.594(0.006) & -0.004(0.007) & 0.004(0.008) \\ -0.046(0.026) & 0.879(0.030) & 0.081(0.031) \\ 0.539(0.027) & 0.875(0.030) & 0.085(0.031)\end{array}\right]$

$\underline{\text { SAP }}$

$\left[\begin{array}{rrr}0.596(0.007) & -0.005(0.008) & 0.001(0.008) \\ -0.149(0.021) & 0.689(0.024) & 0.287(0.026) \\ 0.444(0.023) & 0.685(0.025) & 0.288(0.026)\end{array}\right]$ 


\section{Table 4}

\section{Information Shares of the Exchange Rate, Home-Market Price, and U.S. Price in Price Discovery of Internationally-Traded Equities}

The information shares are the proportion of the innovation variance in the value of asset $i$ that can be attributed to innovations in the price of asset $j$. The estimates are drawn from a VEC model involving the dollar/euro exchange rate, the home-market (XETRA) price, and the U.S. (NYSE) price. That particular order of the three variables is utilized in the triangularization of the covariance matrix. Elements of each row may not sum exactly to 1 due to rounding to 3 decimal places. Bootstrap standard errors are in parentheses.

\begin{tabular}{llll}
\hline & $\begin{array}{l}\text { Exchange Rate } \\
\text { Innovation }\end{array}$ & $\begin{array}{l}\text { XETRA } \\
\text { Innovation }\end{array}$ & $\begin{array}{l}\text { NYSE } \\
\text { Innovation }\end{array}$ \\
\hline DCX & $0.999(0.005)$ & $0.000(0.002)$ & $0.001(0.004)$ \\
$\begin{array}{l}\text { Exchange Rate } \\
\text { XETRA Price }\end{array}$ & $0.007(0.003)$ & $0.906(0.029)$ & $0.087(0.027)$ \\
NYSE Price & $0.073(0.007)$ & $0.838(0.024)$ & $0.089(0.027)$ \\
DT & $0.999(0.004)$ & $0.000(0.002)$ & $0.000(0.002)$ \\
Exchange Rate & $0.000(0.001)$ & $0.991(0.007)$ & $0.009(0.007)$ \\
XETRA Price & $0.049(0.005)$ & $0.942(0.008)$ & $0.009(0.007)$ \\
NYSE Price & $1.000(0.004)$ & $0.000(0.002)$ & $0.000(0.002)$ \\
SAP & $0.006(0.002)$ & $0.798(0.041)$ & $0.196(0.039)$ \\
Exchange Rate & $0.059(0.006)$ & $0.752(0.036)$ & $0.189(0.039)$ \\
XETRA Price & & & \\
NYSE Price & & & \\
\hline
\end{tabular}




\section{Table 5}

\section{Bounds for Information Shares}

Permuting the order of the variables in the Cholesky decomposition of the covariance matrix allows the computation of the upper and lower bounds on information shares. The variable going first in the order has its share maximized and the variable listed last has its share minimized. The table gives the upper and lower bounds for each innovation pair. Only a single value is reported when the upper and lower bounds round to the same number at 3 decimal places.

\begin{tabular}{llll}
\hline & $\begin{array}{l}\text { Exchange Rate } \\
\text { Innovation }\end{array}$ & $\begin{array}{l}\text { XETRA } \\
\text { Innovation }\end{array}$ & $\begin{array}{l}\text { NYSE } \\
\text { Innovation }\end{array}$ \\
\hline DCX & & & $0.001-0.003$ \\
Exchange Rate & 0.998 & 0.000 & $0.086-0.093$ \\
XETRA Price & 0.007 & $0.906-0.901$ & $0.089-0.097$ \\
NYSE Price & $0.072-0.081$ & $0.833-0.838$ & \\
DT & & & 0.000 \\
Exchange Rate & 0.999 & 0.000 & $0.009-0.012$ \\
XETRA Price & 0.000 & $0.988-0.991$ & $0.009-0.012$ \\
NYSE Price & $0.049-0.050$ & $0.938-0.941$ & 0.000 \\
SAP & & & $0.196-0.199$ \\
Exchange Rate & 1.000 & 0.000 & $0.189-0.191$ \\
XETRA Price & $0.006-0.007$ & $0.794-0.797$ & \\
NYSE Price & $0.057-0.058$ & $0.750-0.758$ & \\
\hline
\end{tabular}




\section{Table 6}

\section{Simulation Results}

To assess the effects on information shares of denominating either home or US price in the foreign currency we generate 1,000 datasets of 40,000 observations each by simulating the following data generating process (DGP):

$$
\begin{aligned}
& \Delta E_{t}=-0.01 \Delta E_{t-1}+e_{t}^{e} \\
& \Delta P_{t}^{h}=0.005\left(P_{t-1}^{u}-P_{t-1}^{h}+E_{t-1}\right)-0.01 \Delta P_{t-1}^{u}-0.01 \Delta P_{t-1}^{h}-0.01 \Delta P_{t-2}^{u}-0.01 \Delta P_{t-2}^{h}-0.01 \Delta P_{t-3}^{u}-0.01 \Delta P_{t-3}^{h}+e_{t}^{h} \\
& \Delta P_{t}^{u}=-0.005\left(P_{t-1}^{u}-P_{t-1}^{h}+E_{t-1}\right)-0.01 \Delta P_{t-1}^{u}-0.01 \Delta P_{t-1}^{h}-0.01 \Delta P_{t-2}^{u}-0.01 \Delta P_{t-2}^{h}-0.01 \Delta P_{t-3}^{u}-0.01 \Delta P_{t-3}^{h}+e_{t}^{u}
\end{aligned}
$$

where $e_{t}^{e} \sim N\left(0, \sigma_{e}^{2}\right), e_{t}^{h} \sim N(0,1), e_{t}^{u} \sim N(0,1), \operatorname{Cov}\left(e_{t}^{e}, e_{t}^{h}\right)=\operatorname{Cov}\left(e_{t}^{e}, e_{t}^{u}\right)=\operatorname{Cov}\left(e_{t}^{u}, e_{t}^{h}\right)=0$. All autocorrelations and cross-autocorrelations are zero. The variance of the exchange rate innovation $\left(\sigma_{e}^{2}\right)$ takes on five values, $0.01,0.1,0.5,1$ and 2 . Hence, we have 1,000 times five simulated datasets with 40,000 observations each. In each replication we estimate the trivariate model and the information shares using the modified Hasbrouck method employed in the estimation reported earlier. FX $\Rightarrow$ US ( $F X \Rightarrow$ home) denotes the information share of the exchange rate w.r.t US (home) prices. The US $\Rightarrow$ home columns report the information share of the US market innovations w.r.t home market price and the home $\Rightarrow$ US columns the information share of the home market w.r.t US prices. We also estimate two bivariate ECMs based on time series where we denominate either home market or US market price in the foreign currency and compute the information shares. This is the standard Hasbrouck (1995) approach with two markets. The reported

\begin{tabular}{|c|c|c|c|c|c|c|c|c|c|c|c|}
\hline & \multicolumn{5}{|c|}{ Trivariate model } & \multicolumn{3}{|c|}{$\begin{array}{l}\text { Bivariate model } \\
\text { US price in euros }\end{array}$} & \multicolumn{3}{|c|}{$\begin{array}{c}\text { Bivariate model } \\
\text { home price in dollars }\end{array}$} \\
\hline$\sigma_{e}^{2}$ & $\begin{array}{l}\text { FX } \\
\Rightarrow \\
\text { US }\end{array}$ & $\begin{array}{c}\text { FX } \\
\Rightarrow \\
\text { home }\end{array}$ & $\begin{array}{c}\text { home } \\
\Rightarrow \\
\text { US } \\
\text { (a) }\end{array}$ & $\begin{array}{c}\text { US } \\
\Rightarrow \\
\text { home } \\
\text { (b) }\end{array}$ & $\begin{array}{l}\text { ratio } \\
\text { (a)/(b) }\end{array}$ & $\begin{array}{c}\text { home } \\
\Rightarrow \\
\text { US } \\
\text { (a) }\end{array}$ & $\begin{array}{c}\text { US } \\
\Rightarrow \\
\text { home } \\
\text { (b) }\end{array}$ & $\begin{array}{l}\text { Ratio } \\
\text { (a)/(b) }\end{array}$ & $\begin{array}{c}\text { home } \\
\Rightarrow \\
\text { US } \\
\text { (a) }\end{array}$ & $\begin{array}{c}\text { US } \\
\Rightarrow \\
\text { home } \\
\text { (b) }\end{array}$ & $\begin{array}{l}\text { Ratio } \\
\text { (a)/(b) }\end{array}$ \\
\hline 0.01 & 0.000 & 0.000 & 0.497 & 0.503 & 0.99 & 0.497 & 0.503 & 0.99 & 0.497 & 0.503 & 0.99 \\
\hline 0.1 & 0.005 & 0.005 & 0.496 & 0.499 & 0.99 & 0.496 & 0.504 & 0.98 & 0.501 & 0.499 & 1.00 \\
\hline 0.5 & 0.103 & 0.104 & 0.445 & 0.448 & 0.99 & 0.448 & 0.552 & 0.81 & 0.548 & 0.452 & 1.21 \\
\hline 1 & 0.316 & 0.318 & 0.340 & 0.343 & 0.99 & 0.339 & 0.661 & 0.51 & 0.655 & 0.345 & 1.90 \\
\hline 2 & 0.648 & 0.646 & 0.174 & 0.174 & 1.00 & 0.179 & 0.821 & 0.22 & 0.821 & 0.179 & 4.59 \\
\hline
\end{tabular}
figures are averages of the estimated information shares over the 1,000 replications. The true DGP implies that $\frac{\mathrm{US} \Rightarrow \text { home }}{\text { home } \Rightarrow \mathrm{US}}=1$ for any $\sigma_{e}^{2}$ 
Figure 1

\section{Time-Series Plots of the XETRA and NYSE Stock Prices and the Dollar/Euro Exchange Rate}

The data plotted in the figures shows the midquotes in Frankfurt trading (XETRA) and New York trading (NYSE) for 3 firms, DaimlerChrysler (DCX), Deutsche Telekom (DT), and SAP. In addition, the dollar/euro exchange rate is plotted. Only observations during overlapping trading hours are displayed. The sample period is August 1, 1999 to October 31, 1999.

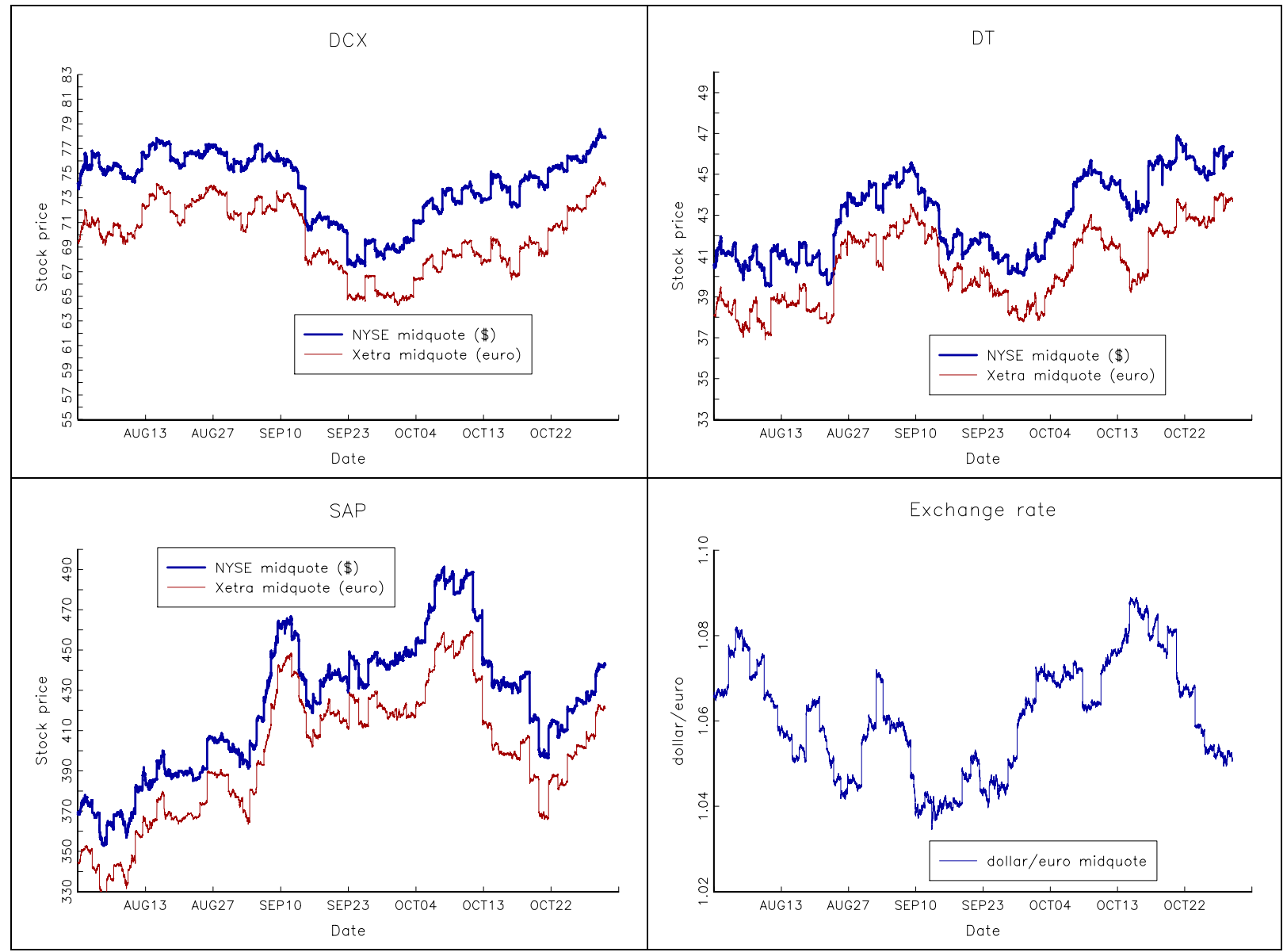


Figure 2

\section{Intra-daily Quoting Intensities}

The figures show the average number of quotes per second for each 5-minute interval over the XETRA and NYSE trading day for the period August 1-September 19, 1999 when XETRA closed at 16:00 GMT.

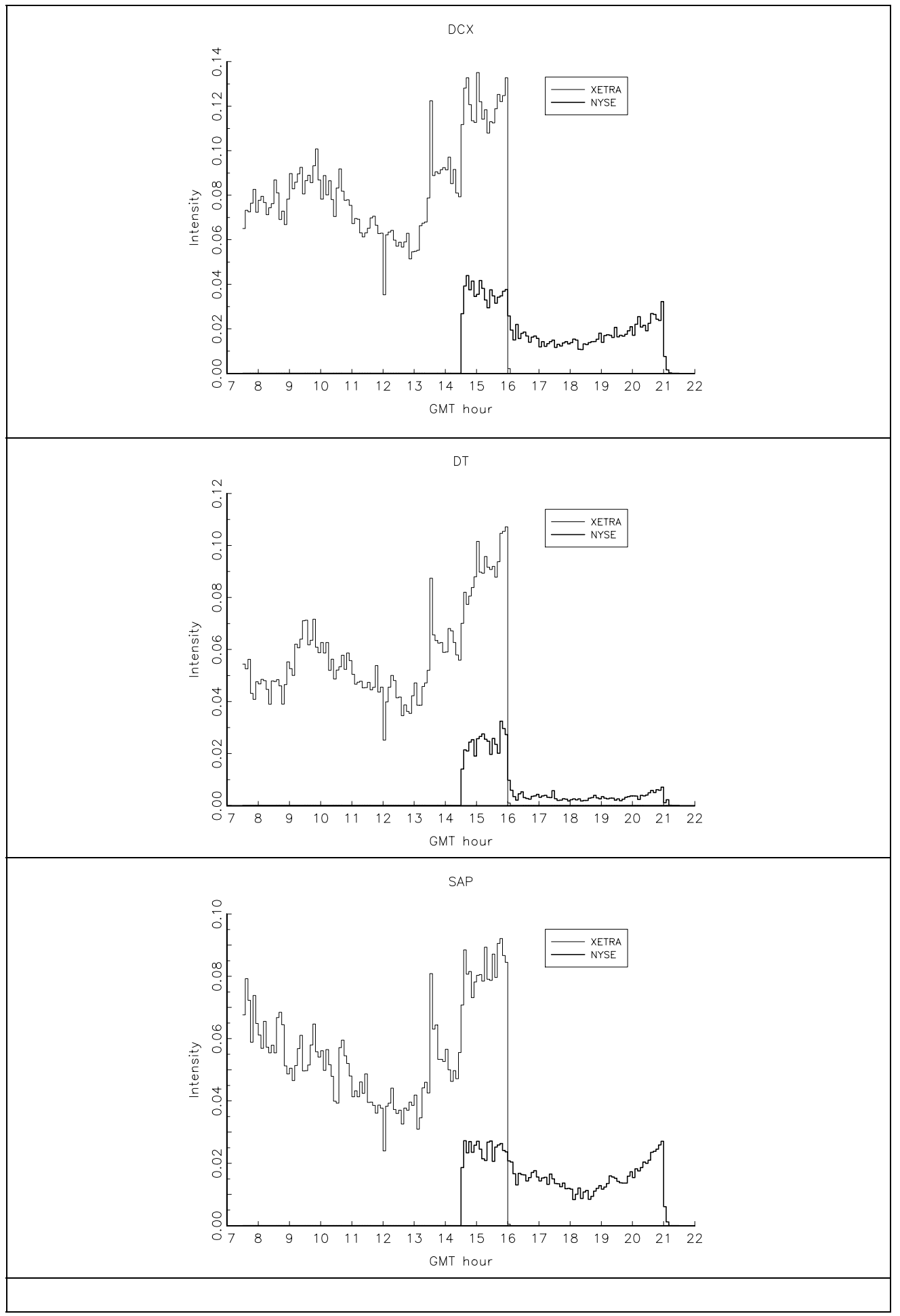




\section{Figure 3}

Impulse Response Functions

The figures trace the long run impact of a one unit innovation in Xetra, NYSE and the exchange rate, respectively, by iterating forward on the estimated VECM in equation (7).

DTE
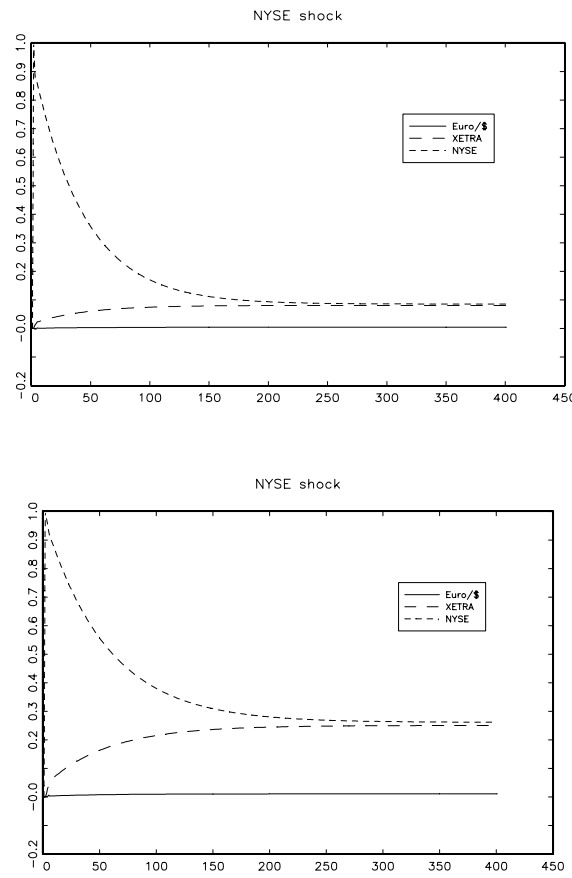

NYSE shoch

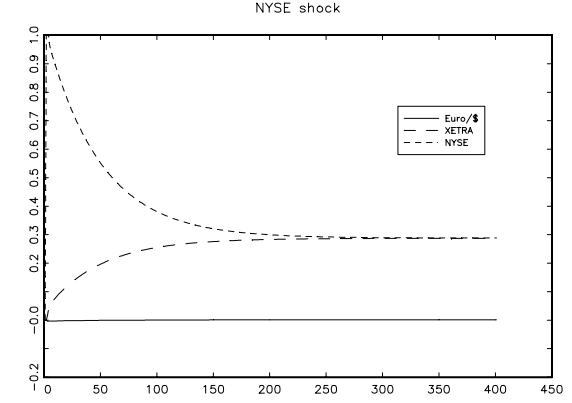

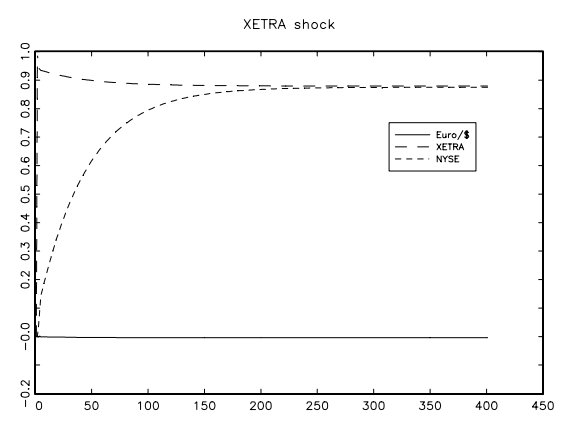

DCX

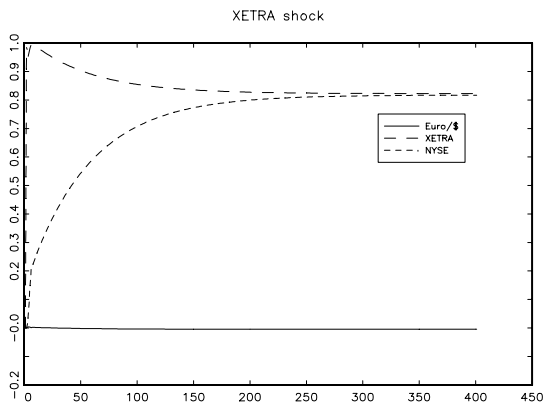

SAP

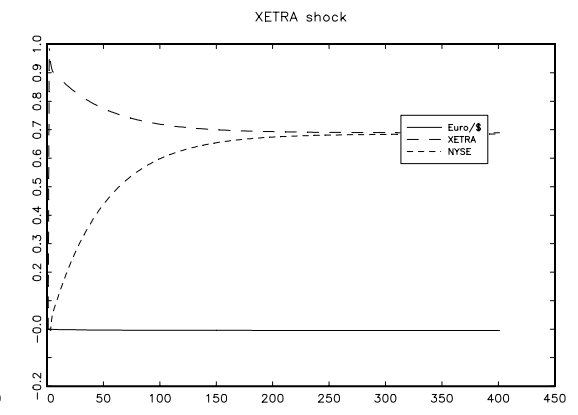

Euro/\$ shook

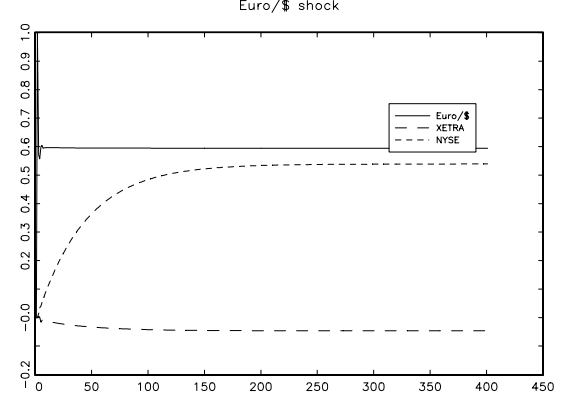

Euro/果 shock

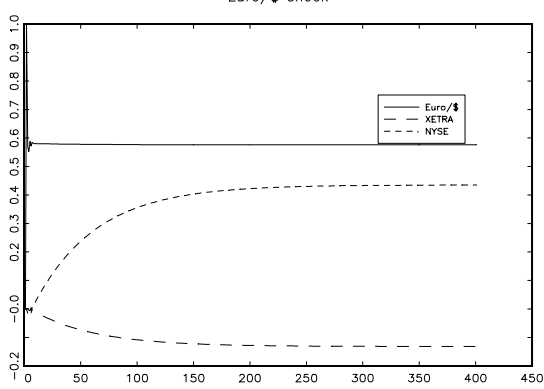

Euro/\$ shock

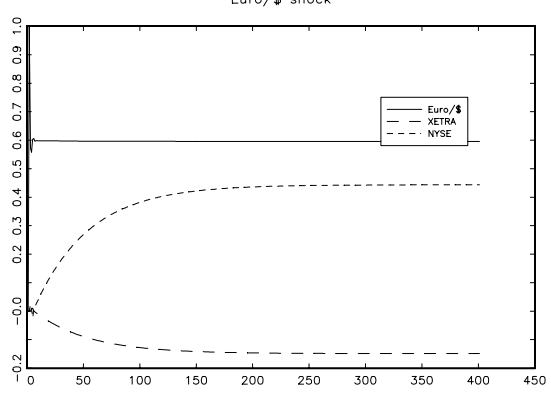


Figure 4

\section{Kernel Density Estimates of Estimated Information Shares}

The figures show the density estimates of the estimated information shares with respect to XETRA and NYSE price innovations based on a sample of 1,000 bootstrap replications. To account for the bounded support of the data, the beta kernel proposed by Chen (1999) with Silverman's (1986) bandwidth selector, adjusted for variable kernels, was employed.

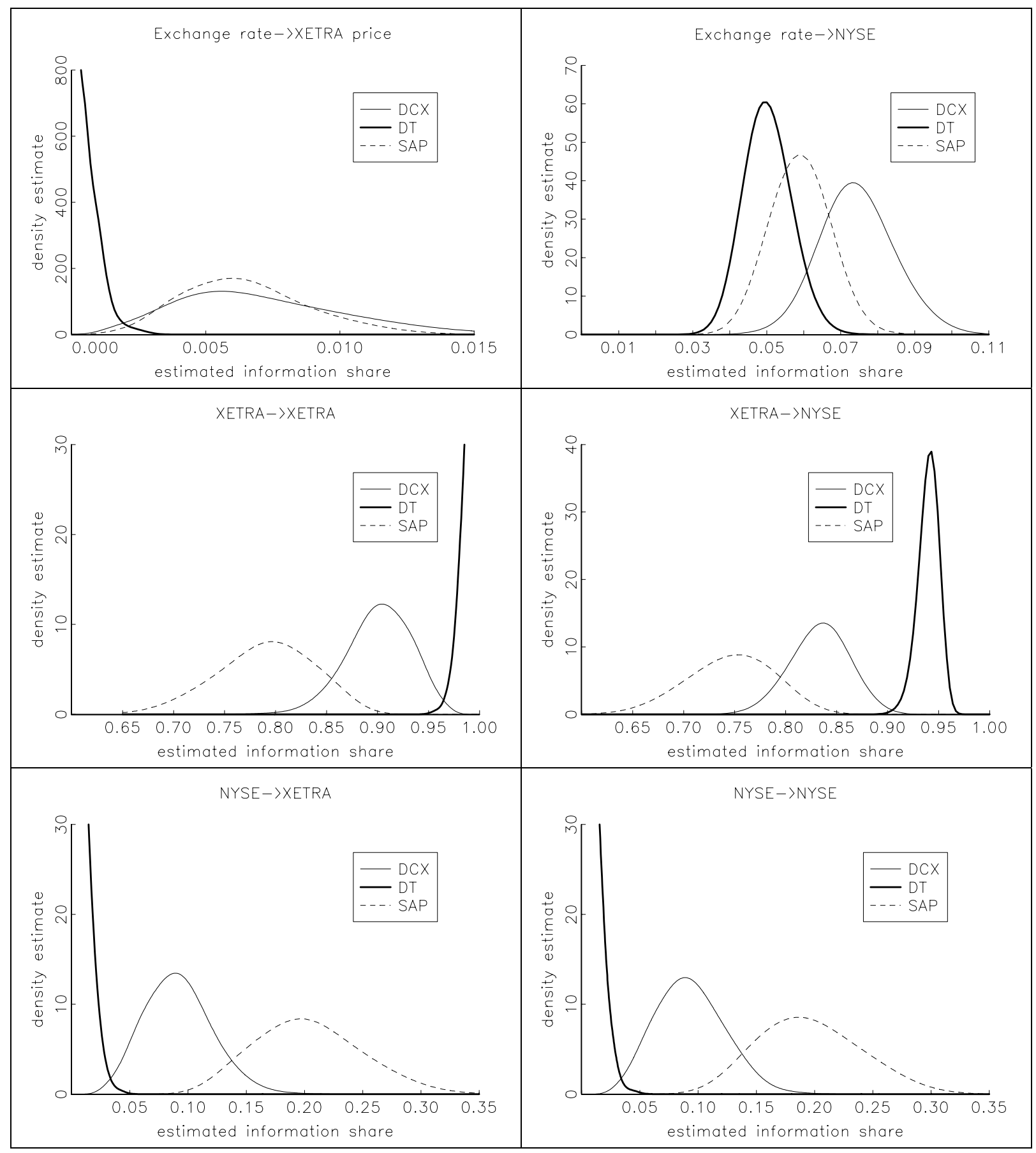

